\title{
Olive oil, diet and colorectal cancer: an ecological study and a hypothesis
}

\author{
Michael Stoneham, Michael Goldacre, Valerie Seagroatt, Leicester Gill
}

\begin{abstract}
Study objectives-Colorectal cancer (CRC) is a common cancer in many western countries and is probably caused in part by dietary factors. Southern European countries have lower incidence rates of CRC than many other western countries. It was postulated that, because olive oil is thought to influence bile salt secretion patterns in rats, it may influence the occurrence of CRC. The purpose of this study was to compare national levels of dietary factors, with particular reference to olive oil, with national differences in CRC incidence.

Design-Ecological study using existing international databases. Incidence rates for CRC, food supply data, and olive oil consumption data were extracted from published sources, combined, and analysed to calculate the correlations between CRC and 10 dietary factors. Associations were then explored using stepwise multiple regression.

Setting-28 countries from four continents.

Main results $-76 \%$ of the intercountry variation in CRC incidence rates was explained by three significant dietary factors-meat, fish and olive oil-in combination. Meat and fish were positively associated, and olive oil was negatively associated, with CRC incidence.

Conclusion-Olive oil may have a protective effect on the development of CRC. The proposed hypothesis is that olive oil may influence secondary bile acid patterns in the colon that, in turn, might influence polyamine metabolism in colonic enterocytes in ways that reduce progression from normal mucosa to adenoma and carcinoma.

(F Epidemiol Community Health 2000;54:756-760)
\end{abstract}

Unit of Health-Care Epidemiology,

Department of Public Health, Oxford

University, Institute of

Health Sciences, Oxford

Correspondence to: Dr Stoneham, Millbarn Medical Centre, 34 London End, Beaconsfield, Bucks HP9 2JH

(michael_david.stoneham@ which.net)

Accepted for publication 3 April 2000 een recognised, and extensively studied, although the results are not clearcut. ${ }^{1-3}$

CRC incidence is particularly high in countries with high meat consumption, for example, Australia and the United States. Mediterranean countries have lower rates than other western countries, which may rise on migration. ${ }^{12}$ It has been suggested that their low rates may be attributable to some extent to their diet, with their high consumption of fruit, vegetables and olive oil. ${ }^{4}$ There is some evidence that high concentrations of secondary bile acids are associated with increased risk of CRC. ${ }^{5}{ }^{6}$ Reduced colonic transit time has been suggested as important in the aetiology of CRC. ${ }^{7}$ Dietary factors-including meat, fat, cereal, vegetables, fruit, milk and olive oilinfluence colonic transit time and the volume of secondary bile acids in the colon. ${ }^{57}$

We have carried out an ecological study in which the association of dietary factors with CRC, and their interrelations, were examined. Our study differs from other ecological studies, such as Armstrong and Doll, ${ }^{3}$ as we have included data on olive oil, which features significantly in the diet of southern European countries, ${ }^{8}$ and has been suggested as an important regulator of cancer in these countries. $^{49-12}$ We also suggest a possible mechanism for the effect of diet on CRC.

\section{Method}

DATA SOURCES

The data were extracted from four international sources. Age standardised incidence rates of CRC in European countries for the year 1990 were obtained from Black et al. ${ }^{13}$ Age standardised CRC incidence data for other countries were estimated for 1990 by calculating the mean of figures abstracted from Cancer Incidence in Five Continents published by the International Agency for Research on Cancer (IARC) for the years 1987 and $1992 .{ }^{14}{ }^{15}$ Data on food supply in 1990, which included cereal, fruit and vegetables, milk, meat, fish and fat intake were obtained from the Food and Agriculture Organisation of the United Nations. ${ }^{8}$ Data on olive oil consumption in 1990 were obtained from the International Olive Oil Council (personal communication). A total of 28 countries with well established data on cancer incidence and on all or most of the food supply of interest were included in the study namely Australia, Austria, Brazil, Canada, China, Colombia, Czech Republic, Denmark, Finland, France, Germany, Greece, Hungary, India, Ireland, Israel, Italy, Japan, Netherlands, New Zealand, Norway, Poland, Portugal, Spain, Sweden, United Kingdom, USA and Yugoslavia. The data used are listed in the appendix.
STATISTICAL METHODS

The association between individual dietary factors and CRC rates was examined first by calculating simple (Pearson) correlation coefficients. CRC rates were used, rather than data for cancers of the colon and rectum separately, because fuller data were available for the former. CRC rates were taken as the combined rates for men and women as these were highly 
Table 1 Correlation between dietary factors and rates of colorectal cancer: correlation coefficients (Pearson's, unadjusted) and partial correlation coefficients (PCC) after controlling separately for each dietary factor

\begin{tabular}{|c|c|c|c|c|c|c|c|c|c|c|}
\hline $\begin{array}{l}\text { Correlation } \\
\text { coefficient }\end{array}$ & Meat & $\begin{array}{l}\text { Animal } \\
\text { fat }\end{array}$ & Total fat & Milk & Fruit & Fish & Vegetable oil & Vegetables & Olive oil & Cereals \\
\hline $\begin{array}{l}\text { Pearson's } \\
\text { PCC controlling for }\end{array}$ & 0.74 & 0.60 & 0.59 & 0.56 & 0.26 & 0.21 & 0.16 & -0.06 & -0.29 & -0.52 \\
\hline Meat & - & 0.04 & -0.03 & 0.21 & -0.01 & 0.41 & -0.08 & -0.29 & -0.47 & -0.31 \\
\hline Animal fat & 0.55 & - & 0.20 & 0.28 & 0.23 & 0.26 & 0.20 & -0.09 & -0.32 & -0.35 \\
\hline Total fat & 0.55 & 0.22 & - & 0.28 & -0.09 & 0.18 & -0.22 & -0.41 & -0.62 & -0.36 \\
\hline Milk & 0.61 & 0.37 & 0.35 & - & 0.03 & 0.22 & 0.05 & -0.09 & -0.36 & -0.27 \\
\hline Fruit & 0.72 & 0.59 & 0.55 & 0.52 & - & 0.19 & -0.10 & -0.24 & -0.57 & -0.46 \\
\hline Fish & 0.78 & 0.61 & 0.58 & 0.57 & 0.25 & - & 0.12 & -0.15 & -0.33 & -0.50 \\
\hline Vegetable oil & 0.73 & 0.60 & 0.60 & 0.55 & 0.23 & 0.18 & - & -0.27 & -0.55 & -0.51 \\
\hline Vegetables & 0.77 & 0.60 & 0.68 & 0.57 & 0.34 & 0.25 & 0.31 & - & -0.40 & -0.52 \\
\hline Olive oil & 0.79 & 0.61 & 0.75 & 0.59 & 0.57 & 0.27 & 0.51 & -0.29 & - & -0.50 \\
\hline Cereals & 0.67 & 0.48 & 0.48 & 0.37 & 0.04 & 0.16 & 0.13 & 0.06 & -0.24 & - \\
\hline
\end{tabular}

correlated with one another $(r=0.95)$ and also because food supply data were available per capita rather than separately for men and women. Because the various dietary factors were correlated with each other, the partial correlation coefficients (PCC) were also calculated. These coefficients measure the correlation for each dietary factor after controlling for the others. This procedure is similar to that used by Armstrong and Doll ${ }^{3}$ in their study of environmental factors, mostly dietary, and cancer.

We then examined the association between the dietary factors and CRC using stepwise regression. This procedure starts by selecting the model in which each individual factor fits the data best. A second factor is selected for inclusion in the model, in combination with the first, as the one in which the model of the two terms again produces the best fit. This procedure is continued until the addition of no other factor produces a significant $(\mathrm{p}<0.05)$ improvement in fit.

Stepwise regression can be problematic as the selection of variables can depend on the criteria used for inclusion. The selection of variables was therefore also carried out using a backward elimination procedure. The model was prepared containing terms for all of the dietary factors. Each factor, in turn, was eliminated from the model and the goodness of fit of the resulting model examined. After each step the factor that produced the least change to the goodness of fit of the model was eliminated. In similar fashion, the factors were eliminated in turn until none of the remaining factors could be eliminated from the model without a significant reduction in the goodness of fit of the model.

We analysed the data using the stepwise procedures outlined above for all the dietary factors excluding olive oil to facilitate comparison with other studies, few of which included olive oil. We then added olive oil to the list of dietary factors and repeated the analysis. The fits of the various models were assessed by determining the percentage of variation explained by each model. To enable the fits of these models to be compared, we adjusted these percentages to allow for the different number of factors included in the models. ${ }^{16}$

\section{Results}

CORRELATION ANALYSIS

Table 1 shows that meat, animal fat and total fat had the highest correlation coefficients with CRC. These factors were also highly correlated with each other $(r>0.75)$. Controlling for meat reduced the correlation with CRC for total fat and for animal fat to negligible levels while that for meat remained after controlling for total fat and animal fat (table 1).

Table 2 Parameters of the fitted models, their standard errors (SE) and the percentages of inter-country variation explained by the models

\begin{tabular}{|c|c|c|c|c|c|c|}
\hline & \multicolumn{5}{|c|}{ Parameters (SE) of fitted models } & \multirow{2}{*}{$\begin{array}{l}\% \text { Inter-country } \\
\text { variation } \\
\text { explained }\end{array}$} \\
\hline & Meat & Fish & Vegetables & Fruit & Olive oil & \\
\hline \multicolumn{7}{|l|}{ Stepwise without olive oil } \\
\hline 1 Meat & $0.23(.04)$ & - & - & - & & 53 \\
\hline 2 Meat + fish & $0.24(.04)$ & $0.15(.07)$ & - & - & & 60 \\
\hline 3 Meat + fish + veg & $0.26(.03)$ & $0.22(.06)$ & $-0.07(.02)$ & - & & 70 \\
\hline \multicolumn{7}{|l|}{ Stepwise including olive oil } \\
\hline 1 Meat & $0.23(.04)$ & - & - & - & - & 53 \\
\hline Meat + olive oil & $0.23(.04)$ & - & - & - & $-0.61(.23)$ & 62 \\
\hline Meat + olive oil + fish & $0.24(.03)$ & $0.18(.06)$ & - & - & $-0.71(.20)$ & 73 \\
\hline 4 Meat + olive oil + fish + fruit & $0.21(.03)$ & $0.17(.05)$ & - & $0.07(.03)$ & $-1.05(.23)$ & 77 \\
\hline \multicolumn{7}{|l|}{ Effect of vegetables and olive oil } \\
\hline Meat + fish + veg & $0.26(.03)$ & $0.22(.06)$ & $-0.07(.02)$ & - & - & 70 \\
\hline Meat + fish + olive oil & $0.24(.03)$ & $0.18(.06)$ & - & - & $-0.71(.20)$ & 73 \\
\hline Meat + fish + veg + olive oil & $0.25(.03)$ & $0.20(.06)$ & $-0.02(.04)$ & - & $-0.58(.35)$ & 72 \\
\hline \multicolumn{7}{|l|}{ Effect of fruit and olive oil } \\
\hline Meat + fish + fruit & $0.24(.04)$ & $0.16(.07)$ & - & $-0.01(.03)$ & & 58 \\
\hline Meat + fish + olive oil & $0.24(.03)$ & $0.18(.06)$ & - & - & $-0.71(.20)$ & 73 \\
\hline Meat + fish + fruit + olive oil & $0.21(.03)$ & $0.17(.05)$ & - & $0.07(.03)$ & $-1.05(.23)$ & 77 \\
\hline \multicolumn{7}{|l|}{ Effect of fruit, vegetables and olive oil } \\
\hline Meat + fish + veg + fruit & $0.24(0.04)$ & $0.23(.06)$ & $-0.09(.03)$ & $0.03(.03)$ & - & 70 \\
\hline Meat + fish + veg + olive oil & $0.24(0.03)$ & $0.18(.06)$ & - & - & $-0.71(.20)$ & 73 \\
\hline Meat + fish + veg + fruit + olive oil & $0.21(0.03)$ & $0.18(.06)$ & $-0.01(.04)$ & $0.07(.03)$ & $-0.97(.36)$ & 76 \\
\hline
\end{tabular}



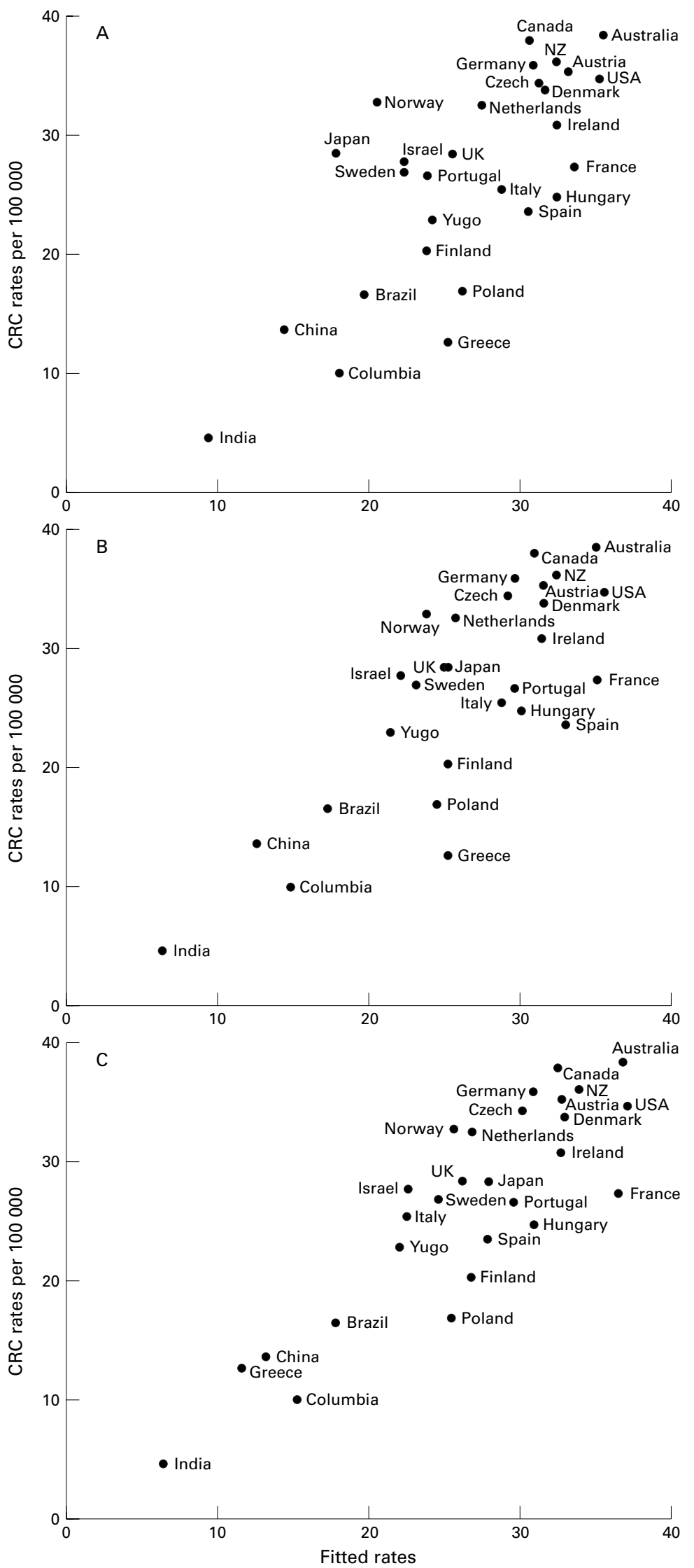

Figure 1 Comparison of observed rates of colorectal cancer (CRC) per 100000 population with the rates obtained from each of the following three fitted models: models consisting of $(A)$ meat; $(B)$ meat + fish and $(C)$ meat + fish + olive oil.
KEY POINTS

- Olive oil ingestion may reduce secondary bile acid activity in the colon.

- Olive oil may have a protective effect on the development of CRC.

- We found that meat and fish combined were positively associated with, and olive oil was negatively associated with, CRC incidence.

- Colonic mucosal diamine oxidase inhibition by secondary bile acids may promote mucosal proliferation and the adenoma/ carcinoma sequence.

\section{REGRESSION ANALYSIS}

We excluded olive oil in the first analysis as many studies of diet and CRC have not included it. The stepwise procedure identified first meat, then fish, and finally vegetables as the significant variables to be included in the model (table 2). The addition of fruit, total fat, vegetable oil, animal fat, meat, milk and cereal did not produce any improvement in fit above that found from the three factor model. The backward procedure produced the same model.

When olive oil was added, the stepwise procedure selected four factors that, in increasing order of magnitude of contribution were: meat, olive oil, fish and fruit (table 2). Vegetables did not contribute to the goodness of fit when olive oil was included in the selection list. The associations between CRC and meat, fish, and fruit were positive, while that with olive oil was negative. The model of meat, fish and olive oil accounted for $76 \%$ of the variation in CRC incidence between countries. The addition of fruit raised this to $80 \%$. The addition of other food factors did not produce any significant improvement. The backward elimination procedure resulted in the same final models.

We explored the effect of fruit and vegetables further. The effect of vegetables alone was reduced by the addition of olive oil to the model of meat + fish + vegetables (the fitted parameter changed from -0.07 , which was significantly different from zero, to -0.02 , which was not; table 2). In contrast the addition of vegetables to the model of meat + fish + olive oil had less of an effect on the fitted parameter for olive oil (table 2). Thus the association of olive oil and CRC was not explained by its association with vegetables. Adding olive oil to the model of meat + fish + fruit produced a significant improvement in fit (its fitted parameter changed from -0.01 to 0.07 ). The addition of fruit to the model of meat + fish + olive oil also improved the fit and increased the apparent effect of olive oil (parameter changed from -0.71 to -1.05 ). Thus fruit only seemed to have an effect when meat, fish and olive oil were included in the model; but olive oil had an effect irrespective of whether fruit was included. Finally, we compared the effect of olive oil on CRC when both fruit and vegetables were included in the model. The results were basically the same as when fruit and vegetables were considered separately. 
Figure 1A-C shows the agreement between the actual CRC rates and those obtained for various fitted models. Figure 1A illustrates the fit of the model with meat alone. Figure 1B shows the fit of the model with meat and fish. It shows that the fitted values for Japan and Norway, both countries with high fish consumption, are now both closer to their observed rates, while those for Greece and Spain were higher than their observed rates. The addition of olive oil to the model of meat + fish (fig 1) improved the fit of the data for Greece and Spain.

\section{Discussion}

DIETARY FACTORS

Ecological studies consistently find that relatively high levels of risk of CRC are associated with high intakes of meat and fat and low intakes of fibre. ${ }^{617}{ }^{18}$ COMA reported that the balance of evidence is that fish consumption is not associated with CRC. ${ }^{1}$ However, there seems to be an additive effect of meat and fish (table 2), which may reflect the overall intake of animal protein and fat.

Vegetarians are generally at lower risk of CRC than meat eaters. ${ }^{19}$ The apparently protective effect of a vegetarian diet, and specifically of fibre, might be attributable to plant components of diet, perhaps antioxidants, or it might result from lack of exposure to meat and fat. The Working Group on Diet and Cancer of the Committee on Medical Aspects of Food and Nutrition Policy (COMA) reported that the summarised evidence on antioxidants is inconclusive. ${ }^{1}$ In our study, simple correlation showed an association between high incidence rates of CRC and low levels of cereal and vegetable consumption. However, multivariate modelling showed that high levels of meat consumption rather than low levels of cereal and vegetables were the important factors. Vegetables played a part in our model when olive oil was omitted, but lost significance when it was included.

The association between CRC and fruit in our study, after adjusting for meat, fish and olive oil, was unexpected. This association may be confounded with some aspect of affluence. The COMA report concluded that there is limited and inconsistent evidence about fruit consumption and CRC. ${ }^{1}$

Olive oil was found to be negatively associated with CRC after allowing for the other dietary factors. The moderating influence of the olive oil effect may be best understood by a consideration of how olive oil and bile salts might interact together.

THE DIAMINE OXIDASE HYPOTHESIS

It is widely believed that bile salts may have some role in the aetiology of CRC. ${ }^{20}$ It has also been suggested that the enzyme diamine oxidase (DAO) may play a part. ${ }^{21}$ DAO is a major catabolic enzyme for histamine. It is found in highest concentration in the ileal mucosa, and also in the colon. ${ }^{22} \mathrm{DAO}$ is thought to have a role in colonic mucosal regulation. ${ }^{23} \mathrm{DAO}$ activity is reduced in vitro by detergent and also by glycochenodeoxycholic acid. ${ }^{24} 25$

The role of secondary bile acids, including deoxycholic acid, in the development of colorectal carcinoma has been well documented. ${ }^{56}$ Deoxycholic acid appears to be reduced in vegetarians. ${ }^{19} 26$ The inhibition of DAO by deoxycholic acid is as yet speculative but possible, in view of in vitro inhibition of DAO by glycochenodeoxycholic acid. ${ }^{25}$ There seems to be a significant reduction in the cholic acid and chenodeoxycholic acid pool in rats given an olive oil diet. ${ }^{27}$ In discussing the role of meat in CRC development, Owen and Hill have suggested that meat, too, may influence deoxycholic $\operatorname{acid}^{56}$ with higher levels of faecal bile acid in populations with a normal western mixed diet. Increases in faecal steroid levels seem to be associated with higher mucosal proliferation rates or colonic adenomas. $^{28-30}$

If meat increases deoxycholic acid in the human colon and rectum, it might be expected that meat could increase CRC incidence because of the inhibition of DAO. If functional DAO is necessary for in vivo control of mucosal proliferation, and if olive oil reduces deoxycholic acid in the human colon and rectum, then it might be expected that olive oil would have a protective effect on CRC incidence because of the greater availability of DAO. It is therefore noteworthy that, in two human studies of the relation between olive oil and CRC, high consumption of olive oil was associated with a decrease in cancer risk. $^{31} 32$

In summary, the DAO hypothesis is that deoxycholic acid, which may be increased by meat consumption and reduced by olive oil consumption, may influence polyamine metabolism in the colorectal mucosa leading to changes in mucosal turnover, polyp formation and the adenoma/carcinoma sequence.

In conclusion, we provide some further ecological support for the involvement of meat in the development of CRC and we show new evidence supporting the hypothesis that olive oil may protect against CRC. We appreciate that the mechanism we have suggested is speculative and also that ecological studies are limited. We suggest that further study is merited, including studies of DAO activity in the colorectal mucosa of people who develop CRC, and further epidemiological studies of CRC and olive oil.

The authors thank: Simon Chevassus (FAO), Jaques Ferlay (IARC), The International Olive Oil Council, Alan Lopez (WHO), Victor Salvo (WHO), David Jernigan (WHO), and Elfreda Douane (WHO), Dave Jagger, Fotios \& Anna Paliatseas, Dr Alison Hill (Oxford), Ian Owens, Andre Tomlin and Marie Dr Alison Hill (Oxford), Ian Owens, Andre Tomlin and Marie Montague (The Prise Project, Oxford), Leslie Martyn and June Kendell (SBNHST Library), Dr Roger Black (Scottish Cancer Surveillance Unit, Edinburgh; formerly of IARC), Dr Derek Jewell (Consultant Physician, Radcliffe Infirmary, Oxford), Dr W Cookson (Asthma Genetics Group, Nuffield Department of Medicine, John Radcliffe Hospital, Oxford), Professor Hermon Dowling and Dr Gerrard Murphy (Gastroenterology Unit, 5th Floor, Thomas Guy House, Guy's Hospital, London SE1 9RT) for their help and advice. We also thank Pam Evans our secretary for endless calm, patience and hard work.

Conflicts of interest: none. 
Appendix Data on colorectal cancer (CRC) rates per 100000 population and food supply per capita (pc) for the year 1990

\begin{tabular}{|c|c|c|c|c|c|c|c|c|c|c|c|c|}
\hline & $\begin{array}{l}\text { CRC male } \\
x / 100000\end{array}$ & $\begin{array}{l}\text { CRC female } \\
x / 100000\end{array}$ & $\begin{array}{l}\text { Total } \\
\text { fat/g/day }\end{array}$ & $\begin{array}{l}\text { Vegetable } \\
\text { fat/g/day }\end{array}$ & $\begin{array}{l}\text { Animal } \\
\text { fat/g/day }\end{array}$ & $\begin{array}{l}\text { Milk } \\
\mathrm{kg} / \mathrm{yr} / \mathrm{pc}\end{array}$ & $\begin{array}{l}\text { Fruit } \\
\text { kg/yr/pc }\end{array}$ & $\begin{array}{l}\text { Vegetables } \\
\text { kg/yr/pc }\end{array}$ & $\begin{array}{l}\text { Meat } \\
\mathrm{kg} / \mathrm{yr} / \mathrm{pc}\end{array}$ & $\begin{array}{l}\text { Fish } \\
k g / y r / p c\end{array}$ & $\begin{array}{l}\text { Cereal } \\
\mathrm{kg} / \mathrm{yr} / \mathrm{pc}\end{array}$ & $\begin{array}{l}\text { Olive oil } \\
\mathrm{kg} / \mathrm{yr} / \mathrm{pc}\end{array}$ \\
\hline Australia & 44.19 & 32.55 & 118.5 & 37.3 & 81.3 & 265.5 & 97.6 & 79 & 118.2 & 17.9 & 90.7 & $<0.01$ \\
\hline Canada & 43.70 & 32.15 & 128 & 58 & 69.9 & 223.4 & 116.2 & 109.7 & 97.2 & 23 & 90.1 & $<0.01$ \\
\hline Czechoslovakia & 43.48 & 25.25 & 130.7 & 40.5 & 90.2 & 172.5 & 61.9 & 78.9 & 100 & 6.0 & 146 & $<0.01$ \\
\hline Austria & 43.10 & 27.40 & 157.6 & 63.1 & 94.5 & 256.2 & 146.5 & 74.5 & 108.3 & 9.2 & 90.9 & $<0.01$ \\
\hline Germany & 41.70 & 30.10 & 140.9 & 49.3 & 91.7 & 226.8 & 115.6 & 87.7 & 98.5 & 12.6 & 98.2 & 0.11 \\
\hline USA & 40.27 & 29.04 & 139.1 & 64.8 & 74.3 & 253.2 & 135.9 & 107.9 & 117.3 & 21.4 & 108.6 & $<0.01$ \\
\hline New Zealand & 40.13 & 32.08 & 131.5 & 32 & 99.5 & 277.3 & 102.2 & 80.6 & 104.9 & 20.3 & 93.9 & $<0.01$ \\
\hline Denmark & 37.40 & 30.20 & 180.8 & 37.5 & 143.4 & 233.8 & 79 & 77.2 & 101.7 & 19.1 & 98.2 & $<0.01$ \\
\hline Netherlands & 36.90 & 28.10 & 137.8 & 56 & 81.8 & 308.8 & 134 & 71.5 & 83.2 & 9.9 & 72.8 & $<0.01$ \\
\hline Ireland & 36.80 & 24.80 & 139.1 & 54.2 & 84.9 & 296 & 66.4 & 71 & 104.7 & 14.2 & 133.6 & $<0.01$ \\
\hline Norway & 36.70 & 28.80 & 129.3 & 45.4 & 84 & 269.5 & 100.6 & 58.7 & 52.8 & 44.3 & 115.4 & $<0.01$ \\
\hline Japan & 35.01 & 21.87 & 79.4 & 42.5 & 36.9 & 66.3 & 57.2 & 107.9 & 41.4 & 71.5 & 144.6 & $<0.01$ \\
\hline France & 34.00 & 20.50 & 163.3 & 56.1 & 107.2 & 284.3 & 82.4 & 120.4 & 110 & 29.5 & 111.9 & 0.48 \\
\hline UK & 33.20 & 23.60 & 135.4 & 48.9 & 86.5 & 224.1 & 77.8 & 89.5 & 74.8 & 18.2 & 93.7 & $<0.01$ \\
\hline Portugal & 32.00 & 21.10 & 124.9 & 63 & 61.8 & 168.7 & 102.7 & 160.7 & 67.9 & 59.7 & 130.2 & 3.50 \\
\hline Italy & 30.40 & 20.30 & 149.8 & 80.2 & 69.7 & 259.7 & 135.5 & 167.8 & 88.8 & 21.8 & 160.9 & 10.98 \\
\hline Israel & 29.80 & 25.63 & 124 & 83.6 & 40.4 & 203.9 & 153.5 & 155.2 & 60.7 & 20.9 & 140.3 & 0.86 \\
\hline Sweden & 29.60 & 24.10 & 120.5 & 42 & 78.5 & 352.7 & 101.6 & 63 & 61.1 & 27.1 & 81.8 & $<0.01$ \\
\hline Spain & 28.00 & 19.20 & 172.7 & 81.1 & 91.6 & 152.4 & 145.7 & 167.1 & 96.1 & 37.8 & 103.4 & 9.88 \\
\hline Hungary & 27.45 & 21.95 & 151.9 & 37.8 & 114 & 154.5 & 72.8 & 87.5 & 104.7 & 4.6 & 144.3 & $<0.01$ \\
\hline Yugoslavia & 26.90 & 18.90 & 111.1 & 45.3 & 65.8 & 172.1 & 63.2 & 77.7 & 68.8 & 3.6 & 213.9 & $<0.01$ \\
\hline Finland & 22.70 & 17.90 & 125.7 & 29.6 & 96.1 & 329.7 & 95.9 & 55.3 & 66.8 & 31.8 & 91.6 & $<0.01$ \\
\hline Poland & 19.77 & 13.93 & 114.1 & 25 & 89.1 & 219.2 & 32.7 & 123.8 & 77.4 & 10.6 & 153.2 & $<0.01$ \\
\hline Brazil & 18.03 & 15.23 & 79.7 & 48.9 & 30.9 & 94.8 & 103.1 & 31.6 & 49.2 & 6.3 & 115.2 & $<0.01$ \\
\hline China & 14.62 & 12.50 & 49.3 & 22.8 & 26.5 & 5.3 & 21.3 & 81.3 & 26.3 & 11.8 & 226 & $<0.01$ \\
\hline Greece & 13.80 & 11.30 & 155 & 90.7 & 64.4 & 226.2 & 196.2 & 226.5 & 73.5 & 20.5 & 151.4 & 20.61 \\
\hline Colombia & 10.00 & 10.00 & 61.2 & 31.3 & 29.8 & 96.8 & 88.2 & 42.6 & 41.7 & 2.6 & 95.9 & $<0.01$ \\
\hline India & 5.29 & 3.81 & 39.8 & 29.2 & 10.6 & 54.7 & 31.4 & 62.9 & 4.9 & 3.8 & 176.3 & $<0.01$ \\
\hline
\end{tabular}

1 Department of Health Committee on Medical Aspects of Food and Nutrition Policy. Nutritional aspects of the development of cancer. London: The Stationary Office, 1998.

2 World Cancer Research Fund and American Institute for Cancer Research. Food, nutrition and the prevention of cancer: a global perspective. Washington DC,USA: American Institute for Cancer Research, 1997.

3 Armstrong B, Doll R. Environmental factors and cancer incidence and mortality in different countries, with special reference to dietary practices. Int $\mathcal{F}$ Cancer $1975 ; 15: 617-31$.

4 Kushi LH, Lenart EB, Willett WC. Health implications of Mediterranean diets in light of contemporary knowledge. 2. Meat, wine, fats, and oils. Am f Clin Nutr 1995;61:1416-
27. $27 \mathrm{~S}$

Hill MJ, Drasar BS, Hawksworth G, et al. Bacteria and aetiology of cancer of large bowel. Lancet 1971;i:95-100.

6 Owen RW. Faecal steroids and colorectal carcinogenesis. Scand F Gastroenterol Suppl 1997;222:76-82.

7 Bingham SA. Mechanisms and experimental and epidemiological evidence relating dietary (non-starch polysaccharides) and starch to protection against large bowel cancer. Proc Nutr Soc 1990;49:153-71.

8 Food and Agricultural Organisation. Food balance sheets. Rome, Italy: 1996.

9 Serra Majem L, La Vecchia C, Ribas Barba L, et al. Changes in diet and mortality from selected cancers in southern Mediterranean countries, 1960-1989. Eur f Clin Nutr 1993;47:S25-34

10 Weisburger JH. Dietary fat and risk of chronic disease: mechanistic insights from experimental studies. $7 \mathrm{Am}$ Diet Assoc 1997;97:S16-23.

11 Benito E, Obrador A, Stiggelbout A, et al. A populationbased case-control study of colorectal cancer in Majorca. I. Dietary factors. Int ₹ Cancer 1990;45:69-76.

12 McMichael AJ, McCall MG, Hartshorne JM, et al. Patterns of gastro-intestinal cancer in European migrants to Australia: the role of dietary change. Int $\mathcal{f}$ Cancer $1980 ; 25$ 431-7.

13 Black RJ, Bray F, Ferlay J, et al. Cancer incidence and mortality in the European Union: cancer registry data and estimates of national incidence for 1990. Eur $\mathcal{F}$ Cancer 1997;33:1075-107.

14 Parkin DM, Muir C, Whelan SL, et al. Cancer incidence in five continents vol 6. Lyon, France: International Agency for Research on Cancer, 1993.

15 Parkin DM, Whelan SL, Ferlay J, et al. Cancer incidence in five continents vol 7. Lyon, France: International Agency for Research on Cancer, 1998.

16 Armitage P, Berry G. Statistical methods in medical research. 2nd ed. Oxford: Blackwell Scientific Publications, 1987: 308.
17 Cummings JH, Bingham SA. Dietary fibre, fermentation and large bowel cancer. Cancer Surv 1987;6:601-21.

18 Hill MJ. Meat and colorectal cancer: what does the evidence show? Eur f Cancer Prev 1997;6:415-17.

19 Hepner GW. Altered bile acid metabolism in vegetarians. Am 7 Dig Dis 1975;20:935-46.

20 Nagengast FM, Grubben MJ, van Munster IP. Role of bile acids in colorectal carcinogenesis. Eur $\mathcal{F}$ Cancer 1995;31: 1067-70.

21 Stoneham $M$. Colorectal carcinoma: some reflections on bile flow through the terminal ileum. Br F Cancer 1997;76: 136-7.

22 Dowling RH. Polyamines in intestinal adaptation and disease. Digestion 1990;46:331-44.

23 Kusche J, Menningen R, Leisten L, et al. Large bowel tumor promotion by diamine oxidase inhibition: animal model promotion by diamine oxidase inhibition: animal mode

24 Sattler J, Hesterberg R, Schmidt U, et al. Inhibition of intestinal diamine oxidase by detergents: a problem for drug formulations with water insoluble agents applied by the intravenous route? Agents Actions 1987;20:270-3

25 Stoneham MD, Young E, Wilkinson JD. Dietary manipulation of fat in chronic urticaria. Fournal of Dermatological Treatment 1993;4:183-5.

26 van Faassen A, Hazen MJ, van den Brandt PA, et al. Bile acids and $\mathrm{pH}$ values in total feces and in fecal water from habitually omnivorous and vegetarian subjects. Am f Clin Nutr 1993;58:917-22.

27 Botham KM, Boyd GS. The effect of dietary fat on bile salt synthesis in rat liver. Biochim Biophys Acta 1983;752:30714

28 Moorehead RJ, Campbell GR, Donaldson JD, et al. Relationship between duodenal bile acids and colorectal neoplasia. Gut 1987;28:1454-9.

29 Terpstra OT, van Blankenstein M, Dees J, al. Abnormal pattern of cell proliferation in the entire colonic mucosa of patients with colon adenoma or cancer. Gastroenterology 1987;92:704-8.

30 Stadler J, Yeung KS, Furrer R, et al. Proliferative activity of rectal mucosa and soluble fecal bile acids in patients with normal colons and in patients with colonic polyps or cancer. Cancer Lett 1988,38:315-20.

31 Bautista D, Obrador A, Moreno V, et al. Ki-ras mutation modifies the protective effect of dietary monounsaturated fat and calcium on sporadic colorectal cancer. Cancer Epidemiol Biomarkers Prev 1997;6:57-61.

32 Braga C, La Vecchia C, Franceschi S, et al. Olive oil, other seasoning fats, and the risk of colorectal carcinoma. Cancer 1998;82:448-53. 